\title{
ANDRAGOGY AS AN APPROACH TO UNIVERSITY \\ AND COLLEGE-LEVEL BIBLICAL STUDIES \\ EDUCATION
}

J H Coetzee

Rand Afrikaans University

\begin{abstract}
This paper focuses on andragogy as an educational approach to Biblical Studies for university and college-level students to bring about maximum learning. The characteristics of the adult student and the role of the lecturer in die didactical process are discussed, resulting in proposals regarding the application of andragogical techniques.
\end{abstract}

\section{Introduction}

Every system of primary, secondary and tertiary education which is primarily based on pedagogy as a teaching principle to a great extent conditions the learners within that system to be dependant, mostly passive receivers of knowledge. The role of the teacher/lecturer in such a system is the actual focal point of the education, although the intention is to put the learner in the centre. A variety of skills and techniques are implemented to transfer information to the learner. Most of the time, however, the teacher/lecturer is to such an extent involved with the contents of the information and with the formal class situation where eighty percent of the communication flows in one direction, namely from the teacher/lecturer to the learner, that the effectiveness of the learning act is questionable. Is not this exactly what is experienced by most learners in the South African context? Lecturing, according to Rogers (1971: 57-58) and de Geus (1988: 72), is actually one of the least efficient ways to convey knowledge. At best, forty percent of what is taught is received; in most situations, it is only about twenty five percent.

The real purpose of learning is to bring about a desired change in the behaviour of the learner. Therefore, all who engage in a learning activity are concerned that the learning should be as effective as possible, so that the objectives of the learning efforts may be achieved. In this regard, what the lecturer does or does not do is of crucial importance. 
According to Meier (1985: 40-43) we are at present in a process of transition from the linear-age learning, which is characterized by its assembly-line thinking, its atomistic approach and its concern for analyzing and categorizing the separate components of reality (the industrial and scientism-age), into the modern knowledge-age of interconnectedness, of a multi-path and selflearning approach to learning, of wholeness of knowledge, the individual, and life itself. Therefore educators and trainers today must develop curricula for man as a whole - body, mind and spirit - for better learning to take place (Meier 1985: 40-42).

This paper focusses on andragogy as a primary educational approach to Biblical Studies for university and college-level students to bring about maximum learning. After explaining the term andragogy, the characteristics of the adult student, the role of the lecturer or facilitator and a few proposals regarding the application of andragogical techniques are dealt with.

\section{Andragogy}

It was Kwowles (1977: 37-38) who waved pedagogy as a means of educating children and adults farewell in favour of andragogy - pedagogy being the principles by means of which children are educated and andragogy being 'the art and science of helping adults learn' (Knowles 1977: 38). The word andragogy originates from the combination of two Greek words, namely aner, meaning 'man', and ago, meaning 'train' or 'educate'. A more balanced viewpoint, however, is that both pedagogy and andragogy are of importance in education and that it is not a matter of the one or the other. In adult education, however, the emphasis should be much more than at present on andragogy.

In the literature on this subject adult education is normally defined as the education of working adults who return to college or university to enrich their lives for some reason or another by means of an appropriate course. Without equating the normal age of college and university-level student with the working adult, I am of opinion that basically the same characteristics of adulthood can be detected in both these categories. Of course their background in experience and therefore their learning needs will differ to a certain extent.

Knowles (1980: 42) mentions two criteria to determine whether a person is an adult or not:

(a) does he/she act like an adult (social definition);

(b) is his/her self-concept that of an adult (psychological definition).

Most educators will agree that the young learners whom we deal with at college and university-level mostly find themselves in an intermediate position with regard to this classification. Socially they do not yet fulfill all the typical roles of the adult like worker, spouse, parent, responsible citizen, and so 
forth. Psychologically they are also transitory with regard to how they see themselves responsible for their own lives and conduct.

Most universities, of course, do make provision for working adults, especially during evening classes and by means of extra-curricular courses. It is also experienced that more and more adults (housewives, teachers on study leave, etc.) attend courses during the normal day-time schedule for the purpose of self-enrichment of further education.

Keeping the above in mind it is obvious that we should make it our concern to approach our students by means of a minimum of pedagogical and a maximum of andragogical principles. In order to bring about real impact on the learning abilities of our students it might be necessary 'to penetrate the comfortable, but misplaced, sense of professional security and identity' (Bright 1989: 7) so often found amongst tertiary educators. The only means by which this could be accomplished is to become aware of the principles of andragogy and their effect on adult-learning and to execute these principles.

Andragogy is rooted in the belief that knowledge is inherently social in nature and that instructors and students can manipulate the experiential knowledge which they obtain. By using this approach 'students begin to experience knowledge as something that is created rather than as something simply passed from teacher to student' (Romer 1985: 4).

\section{Characteristics of the adult learner}

Unlike a child whose self-concept is that of dependency the adult possesses the characteristic self-concept of self-direction and independency. One of the most rewarding experiences is when an adult student discovers that he can take responsibility for his own learning, as he does for other facets of his life (Knowles 1977: 40). It is in the power of the lecturer or facilitator to influence the character of the learning climate in such a way that real impact is made on the learning process. The facilitator conveys in many ways whether his attitude is one of interest in and respect for the students (as adults) or whether he sees them essentially as absorbents of his transmitted knowledge.

Experience is another characteristic of the adult learner. Students have accumulated enough experience in life to be implemented in a contributive manner during their learning process. To a child experience is something that happens to him. An adult, however, is what he has done. This, of course, applies to a larger extent to older learners with more life experience than to younger ones. To be effective, the adult learner must be motivated. This can to a great extent be accomplished by learning which is centered on experience. Therefore, the tutor/facilitator must find out as much as possible about the learners early on in the : urse and throughout to link teaching with their own accumulated knowledge and experience. Adult learning should also be based on giving every opportunity to learners to exercise their reasoning 
faculties and to be helped 'to see the point' for themselves; they should not be expected to learn mechanically. Effective adult learning is also problemcentered. Biblical Studies as subject is extremely suitable to accommodate this kind of learning. The learner must have opportunities to put his new knowledge, skills or behaviour into practice (Cole 1979: 33-36).

Yet another characteristic of the adult learner is his/her readiness to learn. As the adult moves through the different stages of life he requires different and accumulating skills to perform the social roles of adulthood. The continuing change in social roles and need of skills set up changing readiness to learn (Knowles 1977: 46). In this regard the college or university lecturer has an important role to play in detecting the different adulthood skills needed by the students at their stage of life. Involvement in and communication with students on a more social level could be very helpful in this respect.

The last characteristic mentioned by Knowles (1977: 48) is the adult's orientation to learning. Children tend to have a perspective of postponed application on most of their learning. To adults, education is a process of improving their ability to deal with life problems they face now. They tend, therefore, to enter an educational activity in a problem-centered frame of mind.

The working adult learner who takes up studying after a few years of no formal studying faces problems of which the facilitator should be aware. The same applies to young men after their year of military experience. The two main stumbling-blocks are a lack of confidence that he/she really can learn, and the assumption normally made that the same pedagogical principles which were applied at school level could also be applied at college or university level. Both these initial problems can be dealt with in a positive manner by implementing the principles of andragogy and keeping the above characteristics of the adult learner in mind.

In dealing with adult learners one should take notice of the fact that people learn in different ways and that their learning styles can be implemented to benefit their learning. The Kolb-model (Kolb 1976) with its four learning style preferences of divergers, assimilators, convergers and accommodators may be useful in this regard. Divergers prefer concrete to abstract learning situations and reflection to active involvement. Their greatest strengths lie in their imaginative abilities and their capacities to view concrete situations from a number of different stances. Assimilators prefer reflection and abstract situations. They excel in creating theoretical models and in assimilating disparate observations into integrated explanations. Convergers prefer to experiment actively with ideas and test the practical relevance of these ideas. They are interested in the application of theories. Accommodators or executors prefer active involvement in concrete situations. They solve problems on the basis of trial and error and rely on other people for information. They are unstructured in their learning but may criticise as intellectualization other people's attempts at understanding and analysis 
(Sugarman 1985: 265). The identification of these learning styles helps to identify potential learning problems, match participants to activities, and reduce attrition (Knox 1990: 83).

\section{Lecturer or facilitator?}

Most of us have grown up in an academic climate where the assumption is held that the lecturer has the authority to define the subject matter to be acquired and to reinforce this definition by his function as an examiner. Students expect the teacher to act as instructor and their attitude is one of dependence. Many lecturers find it difficult to make adjustments when confronted by adult learners and fall back on the well-tried chalk-and-talk, dictatorial methods which inhibit learning in children and whose deficiencies are simply compounded when applied to adults (Coles 1977: 95). It is not easy to change this role. Strong resistance from within yourself as well as from the students is normally experienced. But for the optimum learning of students it is necessary to change the teacher role into the facilitator role. 'It requires skill and self-restraint on the teacher's part to establish a habit of student/student interaction (Collier 1985: 8).

Collaborative learning as an advanced offspring of andragogy can easily be implemented in Biblical Studies. In the collaborative process, the lecturer's influence is indirect and resembles the behaviour of a facilitator, mediator, or organiser rather than of a traditional pedagogue. The lecturer partakes in the process of mutual inquiry, and relates to the students as knowledgeable colearners. Proper group-orientated techniques are utilised, content materials prepared, and the groups configured. It is very important for the facilitator to resist the urge to interfere with the group process. The facilitator is also responsible for creating an environment that encourages mutual respect, discourages hostile competition, and is non-threatening and democratic.

It is therefore clear that the lecturer should learn what it comprises to act like a mentor or guide who leads the students in the learning process. In order to meet the demands of this process one of the most important skills to obtain is the facilitating of groups, which requires ample knowledge and experience of group dynamics. In this regard the reader can be referred to Rogers (1970) (1983: 203-211), Gordon (1955) (1983: 212-219) and Douglas (1976) (1983: 220-237).

To be able to facilitate with confidence and in an interesting and effective manner the facilitator must be well trained in teaching methods applicable to adults and be aware of the needs and feelings of the students (Coles 1977:135). A two-way communication is as important as variety. Reinforcement of material in different ways stimulates the interest of the learner and makes the learning process enjoyable. Boredom is an enemy of learning (Coles 1977: 92). 


\section{Practical guidelines}

According to Cole (38-41) the facilitator should have a good grasp of the subject otherwise he/she will not be able to inspire the learners. The facilitator, therefore, must always be well prepared and confident. He or she must be equipped with knowledge of various communication methods, including audio-visual aids. Avoid rigidity in content and method. Whenever there is a real need for change from the learners' side, be ready to add to or alter the programme in order to meet with the need. While the lecture is not always the most effective means of communication, do not hesitate to make use of a variety of communication models like discussion groups, role play, fish-bowl, working groups, etc.

Personal and background knowledge of the students always contribute to a better understanding of their learning problems, their learning preferences and interests. It also helps to incorporate their experience into the learning exercise. Refer to and build on the learners' experience during classes and show its relevance. Let the groups learn from each others experience. During every contact period the learners should feel free to communicate with their co-learners as well as with the facilitator at any time.

Knowles (1977: 54, 270-298) is of opinion that the androgogical process involves the following phases:

* The establishment of a climate conducive to adult learning.

This is achieved physically by circular seating arrangements and psychologically by creating a climate of mutual respect among all participants, by emphasising collaborative modes of learning, by establishing an atmosphere of mutual trust, by offering to be supportive, and by emphasising that learning is pleasant.

The attitude an instructor has toward himself and his role quickly conveys to the participants and defines the nature of their relationship. A formal attitude of the tutor will result in a formal, less learningproductive response on the side of the students.

The creation of a structure for participative planning.

Facilitators must involve learners in mutual planning of methods and curricular directions. People will make firm commitments to activities in which they feel they have played a participatory, contributory role. The facilitator, of course, retains responsibility for facilitating the planning activity.

* The diagnosis of needs for learning.

Students should diagnose their own needs for accomplishment of the tasks they have to perform during specific learning activities. By analysing a task the types of action needed could by described before it is performed. 
* The formulation of directions of learning (objectives).

* Facilitators must encourage learners to identify resources and to devise strategies for using such resources to accomplish their objectives.

* $\quad$ Facilitators must help learners to carry out their learning plans.

* Facilitators must involve learners in evaluating their learning, principally through the use of qualitative evaluative modes.

Collier (1985: 6-14) discusses a variety of teaching methods of which only the formal lecture and discussion techniques are mentioned below. While the formal lecture is the least effective method for impact on student learning, it can, however, be assisted by means of visual material like slides, moving films and video-recorders where applicable. Discussion techniques involve students in the expression and clarification of their ideas. Thus difficulties and misunderstandings can be surmounted, a critical approach to new material can be promoted, and oral communication skills can be enhanced. The two principal forms of discussion are the associative (or free) group discussion and the syndicate methods. In an associative group discussion session the group as a whole is given a piece of work for which they are allocated about one third of the time of the period for individual scrutiny. They then discuss their interpretations of the material studied, the object being to bring out into the open the invoiced assumptions which influence and often distort their interpretation of the material. The tutor encourages student/student exchange rather than tutor/student exchange. In a syndicate-based approach a class is divided into 'syndicates' of 4-8 students, and the bulk of the work consists of a series of assignments carried out on a co-operative basis by the syndicates working as teams, for much of the time in the absence of the tutor. The heart of the technique is the intensive debate within the syndicates, which by no means prevents individuals from developing their own distinctive opinions. This technique heightens motivation of the students and stimulates increased involvement in the academic work. It also develops higher order skills like interpretation, analysing, a more critical approach to reading, etc. Deist (1991: 48) should be taken seriously when he suggests 'that planners take a good look at the National Education Crisis Committee's (1987) method of teaching history, in which group discussions play a very important part. Using that didactic approach will enable students to acquire knowledge of the biblical story and, at the same time, a method for using the Bible in making decisions.'

A great help in trying to reach the aims of adult education is to make use of learning contracts (Knowles 1986). A learning contract is a binding, written agreement between the facilitator and the learner. It aims at bringing about certain desired changes in the conduct of the learner by stipulating:

* the learning objectives;

* $\quad$ strategies and resources that can be used to achieve the objectives; 
* proof of accomplishment (e.g. assignments, examination, oral presentation, thesis, etc.);

* criteria of standards for evaluation;

* target dates.

The learning contract ensures mutual planning and negotiation between the learner and the facilitator, which has a positive influence on the motivation of the former. The learner accepts mutual responsibility for his/her own learning process. The more the learner is involved, even in the planning of the contents of the course, the greater is his/her motivation. Therefore, built-in alternatives in the contents of the course, from which the learner may choose according to his/her own preferences and which are stipulated in the learning contract, is a highly motivating strategy.

In the South African context much more empirical research should be done to determine the diagnostic profile of our students and to make the results available to every facilitator in a serviceable form in order to implement the most appropriate andragogical methods. As far as possible differences in social background, language, life experience, learning styles, personal interests, intra- and interrelationships should be taken into account when groups are formed and for mutual assignments.

Especially in the case of first year students it is appropriate to have an introductory session on learning how to learn (Rogers 1971: 71). It would include advice and practice on study methods, taking notes, the use of study guides, writing of an assignment, using the library and so on. Apps (1982) gives valuable clues in this regard.

\section{Conclusion}

Most of the above techniques and principles of andragogy have been used as a basis for facilitating the first and third year Biblical Studies students at the Rand Afrikaans University during the past two years. Overwhelming positive reaction from the first year students was detected by means of questionnaires, especially regarding group work and the social climate of the learning environment. All the students experienced a feeling of involvement. Not all of them could adapt to the group techniques and these students indicated that they prefer working individually. This is a clear indication that the facilitator should bear the different learning styles which students prefer in mind. On the other hand it is to the student's benefit if he/she could implement different learning styles which would broaden not only the required skills but also the understanding of the learning styles of fellow-students, which is needed for effective group-work.

What I myself learned from this experiment was that facilitating a group or small groups is not an easy task. It is, however, something that you gradually grow into with the positive effect of satisfaction on both sides - facilitator as 
well as learner. The biggest reward, however, is that students learn how to learn. And that, to my mind, is what we need, and what we are going to need in future to keep our academic standards at a high level.

For the survival of Biblical Studies as a forming subject, especially in our multicultural and multi-religious society, the facilitator should see his task as an ongoing assessment process to help individuals become more responsive to their own individual cultural and religious sphere as well as to the cultural and religious pluralism in society and to obtain a deeper understanding and appreciation of both these spheres in society on the closer and the wider level.

\section{BIBLIOGRAPHY}

Apps, JW 1982. Study skills for adults returning to school. New York: McGraw-Hill.

Bown, L \& Tomori S H O (eds) 1979. A Handbook of Adult Education for West Africa. London: Hutchinson \& Co.

Bright, BP 1989. Introduction: The epistemological imperative, in Bright, BP (ed), 1-12.

Bright, BP (ed) 1989. Theory and Practice in the Study of Adult Education: The Epostemological Debate. London and New York: Routledge.

Cole, CRA 1979. The adult learner, in Bown, L \& Tomori SHO (eds), 2942.

Coles, EKT 1977. Adult education in developing countries. Oxford: Pergamon Press.

Collier, KG 1985. Teaching Methods in Higher Education: The Changing Scene, with Special Reference to Small-group Work. Higher Education Research and Development 4/1, 3-21.

De Geus, AP 1988. Planning as Learning. Harvard Business Review, 70-74.

Deist, FE 1991. South Africanising Biblical Studies. An epistomological and hermeneutical inquiry. Scriptura 37, 32-50.

Douglas, T (1976) 1983. Observing, recording and evaluating, in Tight, M (ed) $220-237$

Gordon, T (1976) 1983 The group-centered leader, in Tight, M (ed), 212219.

Knowles, MS 1977. The modern practice of adult education: Andragogy versus pedagogy. New York: Association Press.

Knowles, MS 1980. The modern practice of adult education, from pedagogy to andragogy. New York: The Adult Education Company. 